\begin{tabular}{|c|c|}
\hline $\begin{array}{l}\text { Web Revista } \\
\text { O.gloDIALET0 }\end{array}$ & 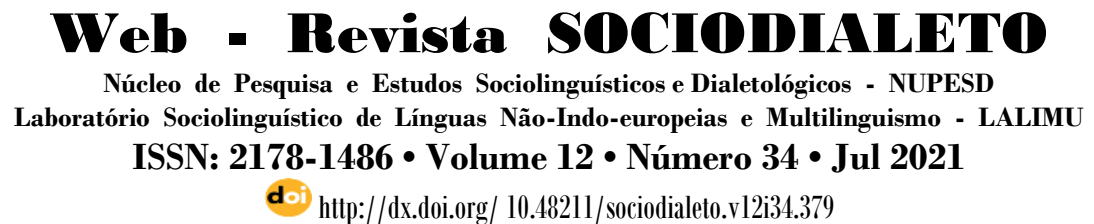 \\
\hline
\end{tabular}

\title{
A LÍNGUA PORTUGUESA PARA ESTRANGEIROS NO MOVIMENTO PELA INTERNACIONALIZAÇÃO DA UNIVERSIDADE TECNOLÓGICA FEDERAL DO PARANÁ, CAMPUS FRANCISCO BELTRÃO
}

THE PORTUGUESE LANGUAGE FOR FOREIGNERS IN THE INTERNATIONALIZATION MOVEMENT OF THE FEDERAL TECHNOLOGICAL UNIVERSTYY OF PARANÁ, FRANCISCO BELTRÃO CAMPUS

\author{
Carina Merkle Lingnau (UTFPR/PPGEFB-UNIOESTE) ${ }^{1}$ \\ carinadebeltrao@gmail.com
}

\begin{abstract}
RESUMO: Com o objetivo de analisar as verdades construídas nos discursos produzidos pelos alunos da disciplina de Comunicação Oral e Escrita do curso de Engenharia de Alimentos e alunos do curso de graduação de Português da UNAM, foi realizado um projeto para troca de emails entre alunos utilizando a língua portuguesa. A metodologia foi levantamento bibliográfico. Cada instituição teve por objetivo desenvolver trocas culturais através da intermediação das plataformas digitais e orientação das professoras do projeto. Como resultados verificamos que a regularidade das sequências analisadas ficou em torno da rotina de trabalho e estudo que envolve o cotidiano desses acadêmicos, o que desencoraja e dificulta as possibilidades de internacionalização via plataforma online.
\end{abstract}

PALAVRAS-CHAVE: Internacionalização; Língua portuguesa para estrangeiros; Discurso; Trocas culturais.

ABSTRACT: In order to analyze the truths constructed in the speeches produced by the students of the Oral and Written Communication course of the Food Engineering course and students of the Portuguese undergraduate course at UNAM, a project was carried out to exchange emails between students using the Portuguese language. The methodology was a bibliographic survey. Each institution aimed to develop cultural exchanges through the intermediation of digital platforms and guidance from the project's teachers. As a result, we verified that the regularity of the sequences analyzed was based on the work and study routine that involves the daily lives of these students, which discourages and hinders the possibilities of internationalization via the online platform.

KEYWORDS: Internationalization; Portuguese for foreigners; Discourse; Cultural exchanges.

\footnotetext{
${ }^{1}$ Possui graduação em Licenciatura em Língua Portuguesa e Inglesa pela Universidade Federal de Santa Catarina. Mestrado em Educação pela Universidade Estadual do Oeste do Paraná. Doutorado em Letras pela Universidade Estadual de Maringá. Professora na graduação da Universidade Tecnológica Federal do Paraná, campus Francisco Beltrão. Docente do Programa de Pós-graduação em Educação da Universidade Estadual do Oeste do Paraná, campus Francisco Beltrão.
} 


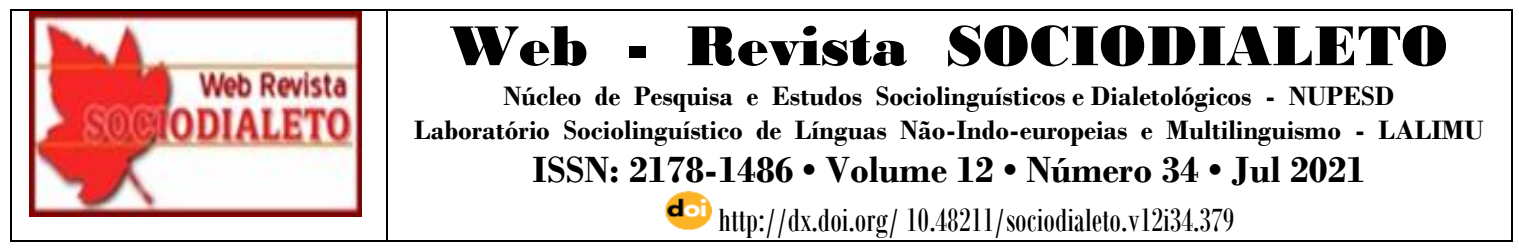

\section{Introdução}

Atualmente estamos vivenciando a internacionalização entre as instituições de ensino superior e esse evento tem sido contemplado também nos cursos de graduação. Entretanto, na Universidade Tecnológica Federal do Paraná campus Francisco Beltrão (UTFPR-FB) isso tem acontecido de forma pontual, sem atingir grande quantidade de alunos. Essa questão nos inquietou e se transformou em nosso problema: diante do pouco número de discentes que faz parte da internacionalização nos cursos de graduação da UTFPR-FB qual a possibilidade de encontrar no Ambiente Virtual de Ensino Aprendizagem (AVEA) uma forma de mobilidade para um maior número de acadêmicos?

Nessa perspectiva nos lançamos à hipótese de que sendo o AVEA um recurso cada vez mais utilizado na UTFPR e na Universidade Nacional de Misiones (UNaM), na qual realizaremos nossa proposta de internacionalização, com possibilidade de resultados positivos na troca cultural, linguística e acadêmica entre as duas universidades. Geograficamente as duas universidades localizadas em Francisco Beltrão, Brasil e Posadas, Argentina (sublinhadas em vermelho), não ficam tão distantes, como mostra a imagem a seguir.

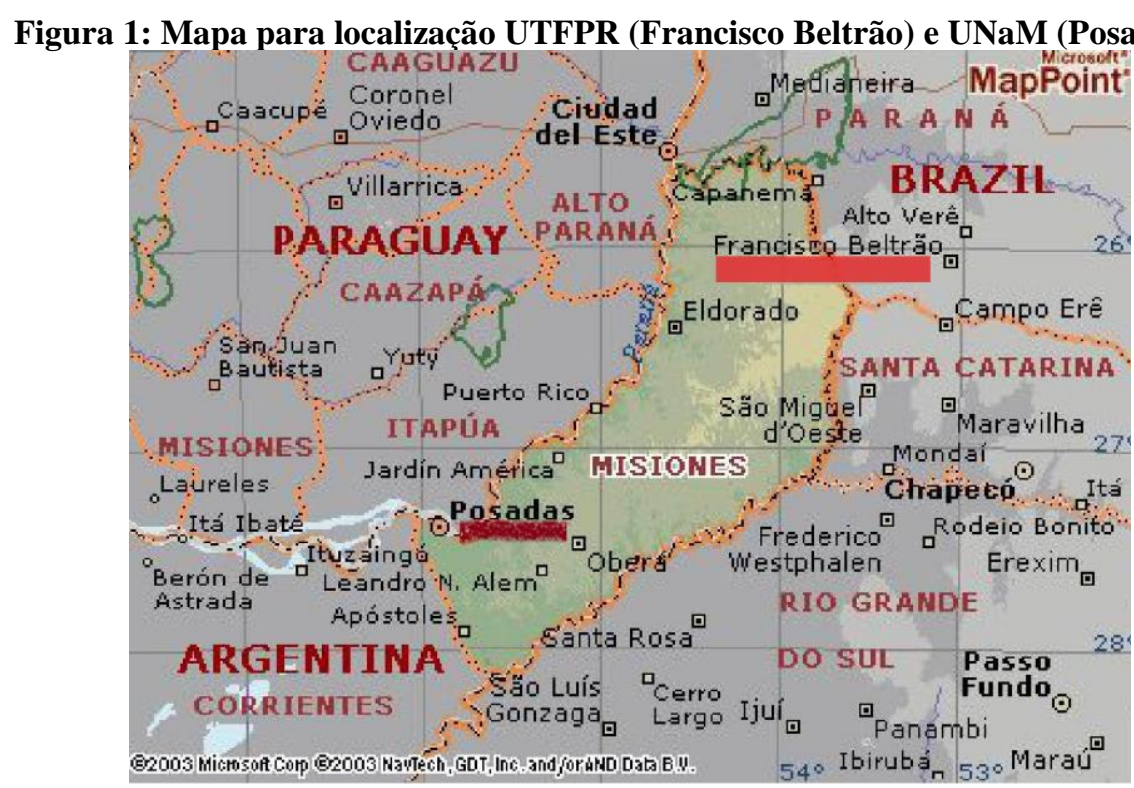

Fonte: http://www.mission.net/ 


\begin{tabular}{|c|c|}
\hline $\begin{array}{r}\text { Web Revista } \\
\text { ODIALET0 }\end{array}$ & 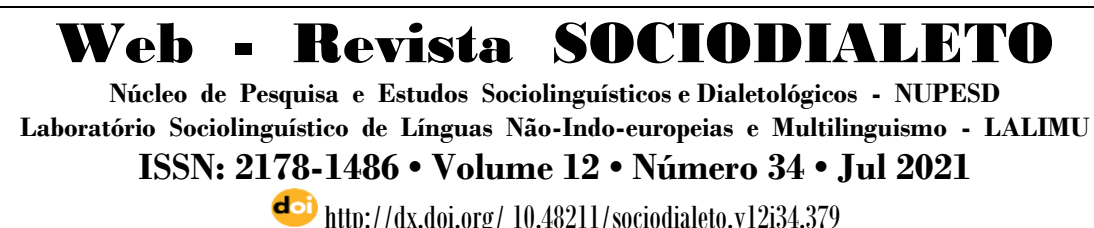 \\
\hline
\end{tabular}

Nessa continuidade, pensamos na internacionalização entre alunos do curso de Engenharia Ambiental da UTFPR-FB e alunos da UNaM com proficiência em português através da disciplina Comunicação oral e escrita. Para discutir este assunto organizamos este artigo da seguinte forma: internacionalização, metodologia, resultados e referências.

\title{
2. Internacionalização
}

Para Morosini (2017, p.115-118) a

\begin{abstract}
internacionalização da educação superior é um conceito complexo, com uma diversidade de termos relacionados, apresentando diversas fases de desenvolvimento. São citadas: a) dimensão internacional presente no século XX, que se caracteriza por ser uma fase incidental mais do que organizada; b) educação internacional - atividade organizada prevalente nos Estados Unidos, entre a segunda guerra mundial e o término da guerra fria, preferentemente por razões políticas e de segurança nacional; e c) internacionalização da educação superior, posterior à guerra fria e com características de um processo estratégico ligado à globalização e à regionalização das sociedades e seu impacto na educação superior[...] Entretanto as discussões sobre a concepção de internacionalização universitária já não apresentam o caráter amplo do período anterior (2000-2003) e abarcam temas como internacionalização e as instituições universitárias. Isto porque, dada como certa a internacionalização, o pensamento mundial isomórfico passa a discutir os efeitos da globalização sobre a instituição universitária.
\end{abstract}

Nesse sentido, pensamos na mobilidade via Mercosul como uma espécie de fortalecimento para os efeitos da globalização de nossas instituições universitárias. Schwartzman (2012, p.28) assevera que

um ponto que chama atenção na tradição das agências brasileiras é a continuidade, (...) é possível afirmar que nenhum outro país manteve, sem interrupção (desde os anos 1970) e com recursos unicamente do Tesouro, programas de bolsas. Esta continuidade, tão pouco usual na nossa administração pública, tem resistido à alternância de governos e aos vícios patrimonialistas de boa parte de nosso serviço público. Graças a este esforço, o sistema brasileiro de pós-graduação e pesquisa é hoje o maior e o melhor estruturado da América Latina. 


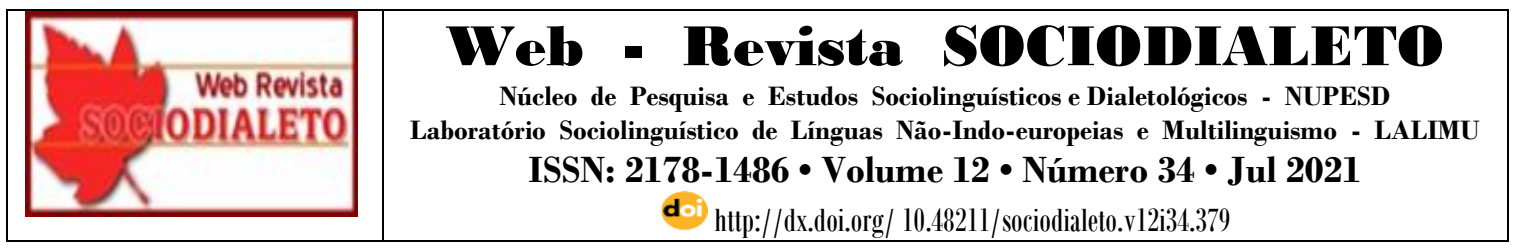

Ao iniciarmos o processo de internacionalização nos cursos de graduação fortalecemos a verticalização futura e expandimos o que atualmente é o sistema maior e melhor estruturado da América Latina. Dessa forma, propor a Argentina para essa parceria não é por acaso, mas por razões como as expressas por Reto (2012, p.52)

a integração negociada desta base de dados (scielo) no ISI (International Scientific Index) ou na Scopus, uma base de dados que engloba cerca de 5000 editores, teria um impacto muito positivo na divulgação da ciência que se produz em português e em espanhol e levaria a um aumento considerável do número e da qualidade destas publicações pelo valor que acrescentariam à carreira acadêmica dos investigadores latinos.

Aproximar a UTFPR-FB e a UNaM foi uma oportunidade de motivar pesquisas e consequentemente sua divulgação em língua portuguesa e/ou espanhola. O sítio da SciELO (Scientific Electronic Library Online), biblioteca eletrônica que agrupa uma coleção selecionada de periódicos científicos, têm em seus indicadores bibliométricos a distribuição dos artigos por ano e país. Em 2015 o Brasil figurava com o primeiro lugar e a Argentina em quinto lugar geral e segundo da América Latina (depois do Brasil) a publicar mais artigos nessa base.

Seguindo esse raciocínio, de acordo com o sítio do Mercado Comum do Sul $(\text { Mercosul) })^{21}$ as línguas oficiais do Mercosul são o português, o espanhol e o guarani, assim o Mercosul acaba associando as línguas e os sujeitos envolvidos nesse contexto. Dessa forma, afirmamos que a disciplina Comunicação oral e escrita, foi a via de acesso entre a UTFPR-FB e a UNaM, é ministrada no campus da UTFPR-FB, obrigatória para todos os cursos, estabelece aproximações com as funções básicas de comunicação e está no agrupamento das disciplinas de ciências humanas da UTFPR.

Alguns trabalhos já vêm sendo realizados nessa área de internacionalização virtual, como na Universidade de Posdam na Alemanha, em que a expressão utilizada é internacionalization at home (internacionalizar em casa) ${ }^{3}$ para acadêmicos que não

2 Disponível em: <http://www.mercosur.int/innovaportal/v/5837/2/innova.front/preguntasfrecuentes\#idiomas $>$. Acesso em: 31/07/2019.

${ }^{3}$ Disponível em: <https://www.uni-potsdam.de/en/wiso/internationalization/mobility/internationalization- 


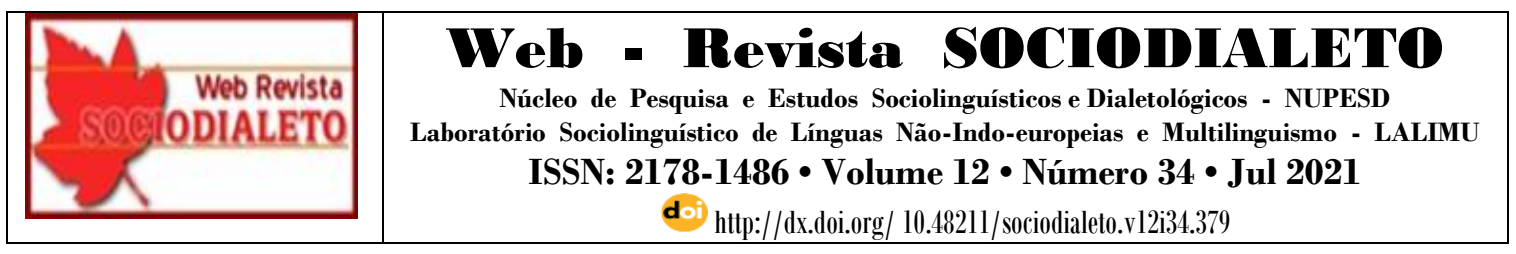

estarão presentes em outros países, mas virtualmente conectados com instituições estrangeiras através dos AVEAs. Na Inglaterra, Universidade de Roehampton, existe o projeto PICASA (Promoting Internationalisation through Cultural and Structural Adaptations - Promovendo Internacionalização através de adaptações culturais e estruturais $)^{4}$ em que utilizando base virtual alunos conseguem adquirir experiências internacionais relacionadas a várias áreas do conhecimento, além de estabelecerem contatos internacionais para desenvolvimento de pesquisa.

No Brasil temos o exemplo da Universidade Estadual de Maringá (UEM) ${ }^{5}$ que em agosto de 2017 estabeleceu convênio de mobilidade internacional virtual com o Chile utilizando para isso cursos e disciplinas online via EAD.

O planejamento é ampliar o número de alunos beneficiados com a internacionalização oferecendo para o grupo todo de Engenharia Ambiental da UTFPRFB, que cursa Comunicação Oral e Escrita, acesso ao AVEA via online (Modular Object-Oriented Dynamic Learning Environment - ambiente dinâmico de aprendizagem modular objeto-orientada) em parceria com a UNaM.

Nesse contexto a plataforma online se apresenta como inovação para a internacionalização na graduação, ou seja, utilizá-la para postar textos interculturais, vídeos, estabelecer comunicação entre as instituições via ferramentas de interação do ambiente de aprendizagem virtual pode gerar resultados positivos em relação ao fortalecimento do contato entre o Brasil e países da América Latina como a Argentina.

A UTFPR oferece as disciplinas dos cursos de graduação utilizando ambiente online para todos os campi, à medida que os docentes buscam se utilizar desse AVEA. O ambiente virtual oferece apoio à aprendizagem, com seu uso o papel é substituído por arquivos digitais além de funcionar como solução para a interação, postagens de vídeos e uso de fóruns para grupos de alunos de determinada disciplina ou curso. Além disso, o

home.html>. Acesso em: 31/07/2019.

${ }^{4}$ Disponível em: <https://www.roehampton.ac.uk/services/learning-and-teaching/research-and- projects/ >. Acesso em: 31/07/2019.$$
\text { Disponível }
$$

$<$ http://www.noticias.uem.br/index.php?option=com_content $\&$ view=article \&id=21971: convenio-comchile-permite-mobilidade-discente-virtual\&catid=986>. Acesso em: 31/07/2019. 


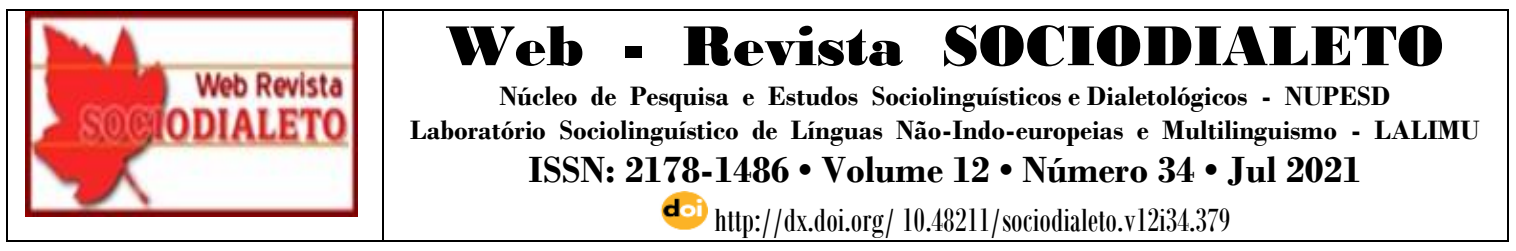

ambiente online não exige conhecimento especializado em informática do professor e nem mesmo do aluno.

A UTFPR tem parcerias com vários países e instituições de ensino superior (IES), uma delas é a UNaM, que também utiliza o email, whatsapp, entre outros, como AVEA. Nesse cenário é fato que o processo de globalização e internacionalização entre os países cria alternativas para a aplicação e desenvolvimento de políticas que atinjam áreas como a educação, cultura, meio ambiente e sociedade, por exemplo. Nessa linha apontamos para o uso do AVEA como meio de instaurar a ampliação da internacionalização da graduação e além disso, proporcionar trocas entre as culturas.

Na intenção de salientar a importância dessa parceria buscamos na professora Catherine Walsh

o conceito de interculturalidade que ela afirma ser central à (re)construção de um pensamento crítico-outro - um pensamento crítico de/ desde outro modo-, precisamente por três razões principais: primeiro porque é vivido e pensado desde a experiência da colonialidade [...]; segundo, porque reflete um pensamento não baseado nos legados eurocêntricos ou da modernidade e, em terceiro, porque tem sua origem no sul, dando assim uma volta à geopolítica dominante do conhecimento que tem tido seu centro no norte global (WALSH, 2005, p. 25).

Assim, os alunos do curso de Engenharia Ambiental teriam a chance de pensar nessa outra instituição, a UNaM, como esse outro, refletir criticamente sobre os sujeitos que frequentam e constroem a instituição com um olhar sem interferência dos legados eurocêntricos, mas vivenciando a experiência de conviver com esse outro na plataforma online e estabelecer com ele as trocas e construção de conhecimento pautados no reconstrução dessa imagem por vezes distorcida do que vem a ser a IES na Argentina e vice-versa.

Nesse sentido, quebrar paradigmas também é inovar, também é internacionalizar com propósito de crescimento social, cultural e intelectual desses sujeitos. O fato do ambiente virtual ser utilizado por usuários do mundo todo também associa os sujeitos de 


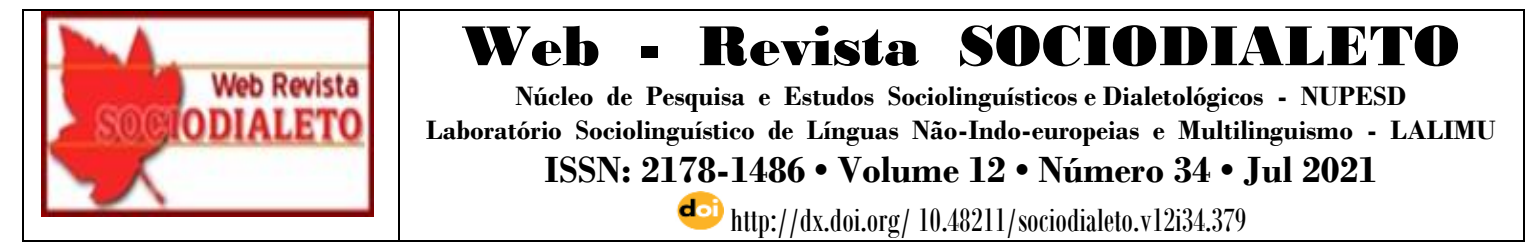

modo a colaborar com o processo de internacionalização via plataforma de AVEA.

A internacionalização no formato virtual através do AVEA no campo da educação atende às necessidades desse tempo histórico e pode contribuir para maior permanência dos alunos na UTFPR-FB, uma vez que os alunos buscam diferenciais na instituição em que estão inseridos.

Nessa conjuntura, o momento histórico brasileiro é de redução orçamentária para a educação, ciência e tecnologia. Considerando o quadro atual político e econômico brasileiro e o crescimento do acesso à informação pela população através de plataformas virtuais, a proposta de internacionalizar via AVEA permite entrada em ambientes institucionais de universidades de outros países a partir do conceito de globalização entre os países na sociedade do conhecimento, diminuindo custos no processo de internacionalização dos sujeitos, otimizando a comunicação e acesso ao conhecimento.

\section{Metodologia}

Esse artigo foi desenvolvido através de abordagem qualitativa utilizando para tanto o uso da pesquisa bibliográfica para o levantamento de trabalhos, artigos e livros sobre o assunto da proposta além de usarmos a pesquisa documental para acessar arquivos físicos e virtuais das universidades e outros órgãos pertinentes para esse trabalho (BAUER \& GASKEL, 2002).

$\mathrm{Na}$ aplicação da proposta utilizamos troca de e-mails e uso do whatsapp através do AVEA coordenado pelas docentes em parceria, basicamente de modo a:

Promover a inovação pedagógica;

Colaborar com os acadêmicos no ambiente de diferentes línguas nativas e culturas;

Fazer a intervenção necessária apoiando todas as atividades acadêmicas, sociais e culturais no ambiente virtual. 


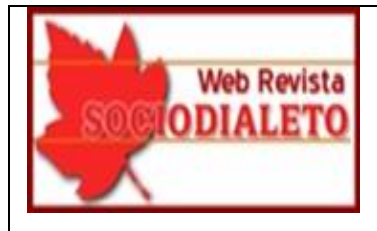

Web - Revista SOCIODIALETO

Núcleo de Pesquisa e Estudos Sociolinguísticos e Dialetológicos - NUPESD

Laboratório Sociolinguístico de Línguas Não-Indo-europeias e Multilinguismo - LALIMU ISSN: 2178-1486 • Volume 12 • Número 34・Jul 2021

doi http://dx.doi.org/ 10.48211/sociodialeto.vl2i34.379

Os acadêmicos da UTFPR-FB e UnaM foram orientados a participarem do projeto de internacionalização interagindo para:

Troca de emails;

Utilizar o aplicativo whatsapp;

Conhecer a língua portuguesa;

Acessar a internet.

Desenvolver competências sociais e culturais que permitam participar nas atividades.

\section{Resultados}

Para analisarmos os dados propostos, percebemos em um primeiro momento que dos cinco acadêmicos da UTFPR-FB envolvidos no processo de internacionalização em casa, apenas uma acadêmica teve sucesso nas trocas de email e uso do whatsapp com acadêmicos da UNaM. A imagem a seguir identifica a sequência de conversa que ocorreu via aplicativo whatsapp. 
Núcleo de Pesquisa e Estudos Sociolinguísticos e Dialetológicos - NUPESD

Laboratório Sociolinguístico de Línguas Não-Indo-europeias e Multilinguismo - LALIMU ISSN: 2178-1486 • Volume 12 • Número 34・Jul 2021

doi) http://dx.doi.org/ 10.4821l/sociodialeto.vl2i34.379

Figura 2 - Mensagens de texto e áudio via whatsapp
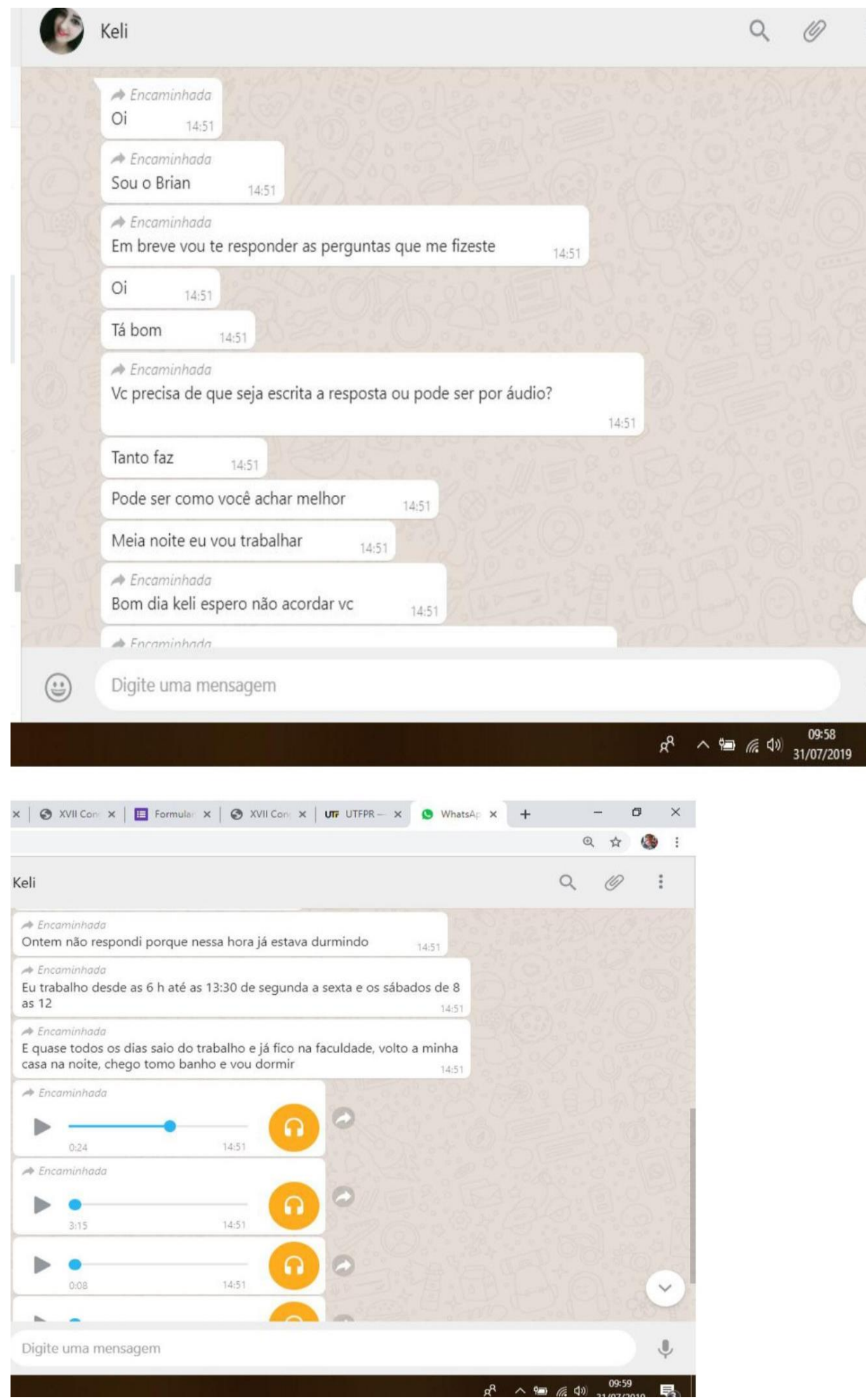

Fonte: arquivo pessoal. 


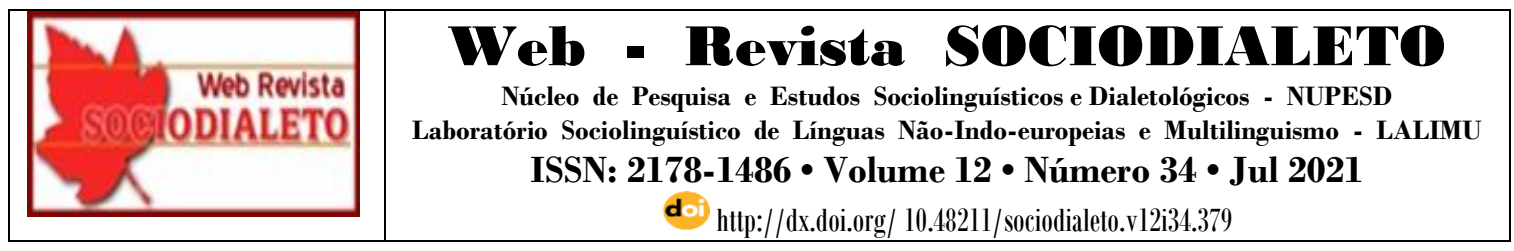

Para tanto, verificamos que a regularidade das sequências analisadas ficou em torno da rotina de trabalho e estudo que envolve o cotidiano desses acadêmicos, o que desencoraja e dificulta as possibilidades de internacionalização via plataforma AVEA.

As sequências do áudio seguem abaixo:

Brian - Nesse áudio vou tentar responder às suas perguntas, se eu não respondi antes é porque eu estava em aula, recém cheguei na minha casa.

Keli - Que legal, é bom não precisar pagar o aluguel, em que período você está? Eu cheguei da faculdade às 18h20, daí fui dormir... Acordei faz uma meia hora, eram 22 h30 quando eu acordei. Aí levantei, tomei um banho, dei uma organizada na casa, porque amanhã é sexta-feira, é dia de faxina...

Brian - Você me perguntou por meus pais, o meu pai mora em uma cidade que se chama Leandro N. Alem que fica a $80 \mathrm{~km}$ daqui (Posadas), foi onde eu nasci, me criei. Morei aí até os 12 anos de idade e daí eu fui morar com a minha mãe onde ela mora agora que é na localidade de San Pedro, Misiones, que fica a 250/300 km daqui de Posadas. Ela mora lá por causa do trabalho dela, ela é mestre de ensino fundamental. Eu, enquanto minhas condições aqui, eu to morando agora numa casa, não faz muito tempo, acho que faz em torno de um mês e meio, dois. Antes disso eu estava morando num apartamento, agora eu não estou pagando mais porque eu cuido da casa, então não pago, mas antes eu pagava o aluguel do apartamento. Depois você perguntou sobre o meu trabalho, o meu trabalho não tem nada a ver com meu curso de graduação, trabalho no que nós chamamos aqui de círculo de bioquímicos, e eu faço tudo da parte administrativa para os bioquímicos, quer dizer, eu faço todos os trâmites que eles deveriam fazer com as obras sociais, bom é isso que eu faço. Depois que eu me formar ainda não sei bem o que eu vou fazer, gostaria de continuar na área das letras, mas por enquanto aqui não há nada relacionado ao idioma português. Se eu conseguisse alguma bolsa para ir estudar nessa universidade que você falou (UTFPR), gostaria de fazer isso, mas no momento ainda nem pesquisei nada disso, porque ainda falta muito para me formar. 


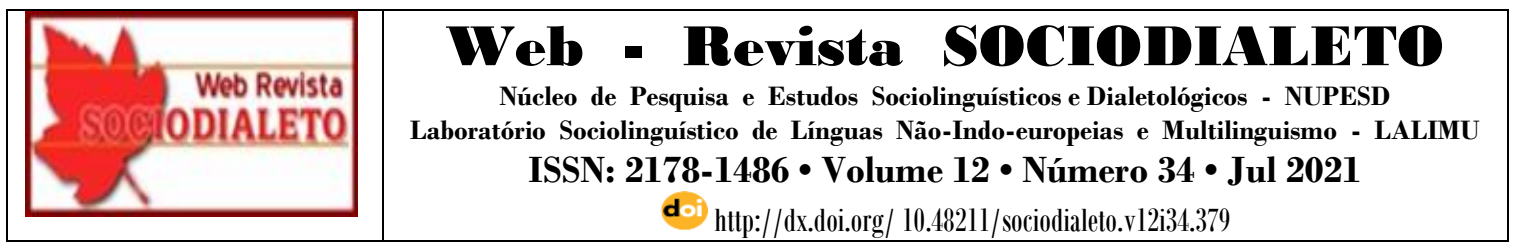

O trecho do áudio também concentra situações da dificuldade do cotidiano marcado pelo trabalho, ajustes financeiros e, nesse sentido, falta de tempo para atividades como engajamento em projetos extra classe.

Assim, através da parceria entre a UTFPR-FB e a UNaM almejamos futuramente efetivar mais trocas entre as duas instituições via ambiente virtual de aprendizagem e possibilidade de agregarmos outras áreas de conhecimento no processo de internacionalização entre as duas universidades.

A expectativa é que os acadêmicos possam adquirir uma melhor compreensão das diferenças e semelhanças dos aspectos culturais, linguísticos e cotidianos entre a sua universidade e a do outro.

Esse esforço em unir as duas instituições pretende impactar na permanência, motivação, crescimento e autonomia desses acadêmicos, docentes e outros servidores envolvidos na proposta, otimizando projetos e pesquisas presentes e futuras.

\section{Referências}

BAUER, M. W; GASKEL, G. Pesquisa qualitativa com texto, imagem e som: um manual prático I tradução de Pedrinho A. Guareschi. Petrópolis, RJ : Vozes, 2002.

DA NÓBREGA, M. H. Políticas linguísticas e internacionalização da língua portuguesa: desafios para a inovação. Revista de Estudos da Linguagem, v. 24, 2016, p. 417-445.

FISCHER, R. M. B. Foucault e a análise do discurso em educação. Cadernos de Pesquisa (Fundação Carlos Chagas), São Paulo (SP), v. 114, 2001, p. 197-223.

FOUCAULT, M. A arqueologia do saber: Tradução Luiz Felipe Baeta Neves. $8^{\text {a }}$.ed Rio de Janeiro: Forense Universitária, 2014.

KNOBEL, M. Brazil: Study-abroad initiative needs careful study. 18 December 2011. Disponível em:

<http://www.universityworldnews.com/article.php?story=20111216171338689>. Acesso em: 01 de dez. 2015.

KNOBEL, M. Ensino superior: Ciência sem Fronteiras. Programa Ensino Superior da UNIVESP TV, 07 de março de 2016. Disponível em: https://www.youtube.com/watch?v=G0JgUUl4FHc. Acesso em: 18 jan. 2017.

KRAWCZYK, N. R. As Políticas de Internacionalização das Universidades no Brasil: o caso da regionalização no Mercosul. Políticas Educativas, v. 1, 2008, p. 32-47. 


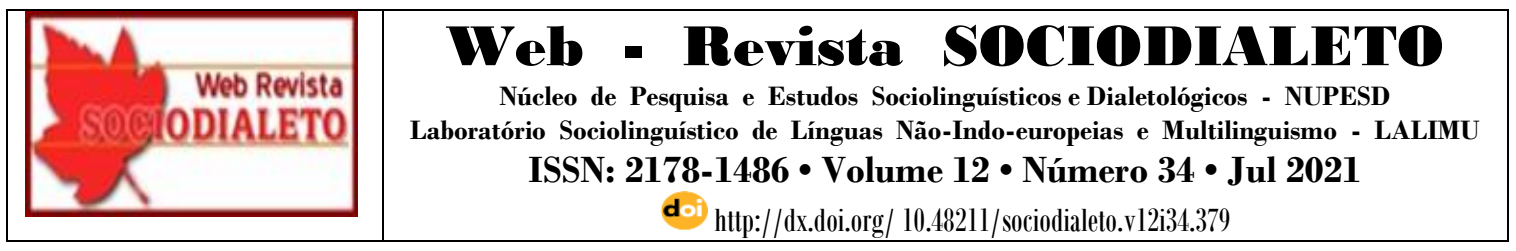

LIMA, M. C. L. A internacionalização da educação: qual o rumo da educação superior? Aula pública Ópera Mundi gravada no Câmpus UNESP Bauru - Tvunesp, 05 de maio de 2014. Disponível em: https://www.youtube.com/watch?v=rkUB61_i5ZM. Acesso em: 18 jan. 2017.

MOROSINI, M. C. Internacionalização da Educação Superior no Brasil pós- LDB: o impacto das sociedades tecnologicamente avançadas. In: Mariluce Bittar; João Ferreira de Oliveira; Marília Costa Morosini. (Org.). Educação superior no Brasil - 10 anos pós-LDB. 1ed.Brasília - DF: INEP, 2008. v. 2, p. 285-304.

MOROSINI, M. C. Internacionalização da educação superior no Brasil: a produção recente em teses e dissertações. Educação em Revista (online), 2017.

MULLER, C.C. EAD nas organizações. 1ed. Curitiba, PR: IESDE, 2012.

RETO, L. (org) et al. Potencial Econômico da Língua Portuguesa. Lisboa: Leya, 2012.

SCHWARTZMAN, S; Castro, C. M; H Barros; Ito-Adler, J. Cem mil bolsas no Exterior. Interesse Nacional, 2012, v. 2, p. 25-36.

VEYNE, P. Foucault: seu pensamento, sua pessoa. Trad. Marcelo Jacques de Morais. Rio de Janeiro: Civilização Brasileira, 2011.

WALSH, C. Pensamiento crítico y matriz (de) colonial-reflexiones lationoamericanas. Quito: Abya-Yala, 2005. 